\title{
Are preterm birth and intra-uterine growth restriction more common in Western Australian children of immigrant backgrounds? A population based data linkage study
}

Ifrah Abdullahi ${ }^{1,2}$, Kingsley Wong ${ }^{1}$, Emma Glasson ${ }^{1}$, Raewyn Mutch ${ }^{1,2,3}$, Nicholas de Klerk ${ }^{1}$, Jenny Downs ${ }^{1,4}$, Sarah Cherian ${ }^{2,3}$ and Helen Leonard ${ }^{1 *}$ (D)

\begin{abstract}
Background: To compare the prevalence of preterm birth, post term birth, intra-uterine growth restriction and distribution of Apgar scores in offspring of foreign-born women in Western Australia with that of their Australianborn non-Indigenous and Indigenous counterparts.

Methods: A population-based linked data study, involving 767,623 singleton births in Western Australia between 1980 and 2010 was undertaken. Neonatal outcomes included preterm birth, post term births, intra-uterine growth restriction (assessed using the proportion of optimal birth weight) and low Apgar scores. These were compared amongst foreign-born women from low, lower-middle, upper middle and high income countries and Australianborn non-Indigenous and Indigenous women over two different time periods using multinomial logistic regression adjusted for covariates.
\end{abstract}

Results: Compared with Australian born non-Indigenous women, foreign-born women from low income countries were at some increased risk of extreme preterm (aRRR 1.59, 95\% Cl 0.87, 2.89) and very early preterm (aRRR 1.63, $95 \%$ Cl 0.92, 2.89) births during the period from 1980 to 1996. During the period from 1997 to 2010 they were also at some risk of extreme preterm (aRRR 1.42,95\% Cl 0.98, 2.04) very early preterm (aRRR 1.34,95\% Cl 1.11, 1.62) and post term birth (aRRR 1.93, 95\% Cl 0.99, 3.78). During this second time period, other adverse outcomes for children of foreign-born women from low income and middle income countries included increases in severe (aRRR 1.69, 95\% Cl 1.30, 2.20; aRRR 1.72, 95\% Cl 1.53, 1.93), moderate (aRRR 1.54, 95\% Cl 1.32, 1.81; aRRR 1.59, 95\% Cl 1.48, 1.70) and mild (aRRR 1.28, 95\% Cl 1.14, 1.43; aRRR 1.31,95\% Cl 1.25, 1.38) IUGR compared to children of Australian-born non-Indigenous mothers. Uniformly higher risks of adverse outcomes were also demonstrated for infants of Indigenous mothers.

Conclusions: Our findings illustrate the vulnerabilities of children born to foreign women from low and middleincome countries. The need for exploratory research examining mechanisms contributing to poorer birth outcomes following resettlement in a developed nation is highlighted. There is also a need to develop targeted interventions to improve outcomes for these women and their families.

Keywords: Preterm birth, Growth restriction, Apgar score, Immigrant mothers, Data linkage

\footnotetext{
* Correspondence: Helen.leonard@telethonkids.org.au

${ }^{1}$ Telethon Kids Institute, The University of Western Australia, PO Box 855,

West Perth, WA 6872, Australia

Full list of author information is available at the end of the article
}

(c) The Author(s). 2019 Open Access This article is distributed under the terms of the Creative Commons Attribution 4.0 International License (http://creativecommons.org/licenses/by/4.0/), which permits unrestricted use, distribution, and reproduction in any medium, provided you give appropriate credit to the original author(s) and the source, provide a link to the Creative Commons license, and indicate if changes were made. The Creative Commons Public Domain Dedication waiver (http://creativecommons.org/publicdomain/zero/1.0/) applies to the data made available in this article, unless otherwise stated. 


\section{Background}

Relationships between adverse pregnancy and birth outcomes such as preterm birth, intra-uterine growth restriction (IUGR) and low Apgar scores and increased infant morbidity and mortality are well-recognised [1-8]. There is also a further body of research evidence linking abnormal pregnancy and birth outcomes to the development of neurodevelopmental disorders and child disability $[2,5,8,9]$. For instance, associations between the presence of IUGR and subsequent intellectual disability (ID) have been demonstrated in Western Australian (WA) population-based research while premature children with extremely low and very low birth weights also have an increased risk of autism spectrum disorders (ASD) [8-10].

Several studies have found that foreign-born women living in developed countries are at increased risk of adverse obstetric and perinatal outcomes including preterm delivery, low birth weight, IUGR, Caesarean section, postpartum haemorrhage and neonatal mortality and infection [11-17]. Obstetric profiles, including maternal medical conditions and pregnancy complications, of foreign-born women of culturally and linguistically diverse (CALD) backgrounds have also been compared with those of Australian-born women [11, 18, 19] using population-based data linkage. In these studies foreignborn women, especially those from Sub-Saharan Africa, Southeast Asia and Southern and Central Asia, were more likely to undergo emergency Caesarean section, often because of failure of labour to progress and fetal distress $[18,19]$. They were also at increased risk of gestational diabetes, pre-labour rupture of membranes, perineal laceration and post-partum haemorrhage [11]. Foreign-born mothers at risk have often been categorised by region, or for an individual country of birth the numbers may have been too small to establish any meaningful risk profiles [13, 16]. Findings have been variable [20], with only some identifying a relationship with preterm birth [14]. The literature demonstrates the variability in the accuracy of the measurement of fetal growth in children of immigrant backgrounds [15, 16], and suggests that the use of fetal and newborn charts as single diagnostic tools (birthweight and gestational age charts) in determining perinatal outcomes may be debatable [21, 22].

Australia is a multiethnic society with just over a quarter of citizens (28\%) born overseas [23], including a smaller subset of refugees. Overseas migration and resettlement is predominantly from Europe with smaller numbers from North Africa, Middle East, South East Asia and Sub-Saharan Africa [20, 24, 25]. Although research to date documenting pregnancy and birth outcomes among these foreign-born women suggests that their obstetric profiles may differ from those of
Australian-born women, the body of evidence remains limited. The aim of this current study was to compare the prevalence of preterm and post term births, intrauterine growth restriction and distribution of Apgar scores in offspring of foreign-born women in WA with that of their Australian-born Caucasian and Indigenous counterparts.

\section{Methods}

\section{Study population and data sources}

A retrospective cohort study of children born in WA (1980 to 2010) was conducted using de-identified linked population-based data from the WA Midwives Notification System (MNS) and the WA Birth Register. The MNS is a statutory database of pregnancy, birth and neonatal information collected by attending midwives, on all births of at least 20 weeks' gestation or at least $400 \mathrm{~g}$ in weight (if unknown gestational age) and includes maternal and infant characteristics and infant outcomes. For this study, multiple births were excluded because they are associated both with poorer birth outcomes and country of birth [26]. The WA Birth Register contains all registered births and includes maternal, paternal and infant demographic characteristics. The birth cohort was subdivided into two time periods (P1; 1980 to 1996 and P2; 1997 to 2010), to allow for adjustment for smoking which was only collected after 1996, and because of changes in migration patterns over time.

\section{Maternal variables}

Maternal variables collected were maternal age (maternal age in years at the time of delivery), marital status (never married, widowed, divorced, separated, married and unknown), parity (the number of live born and stillbirths a woman has had leading up to this particular pregnancy), and smoking (a binary variable only collected in the MNS from September 1997).

Six categories were created using the maternal country of birth (MCB) variable, available from the Birth Register: 1) Australian-born mothers of non-Indigenous backgrounds (ANI), 2) Australian-born mothers of Indigenous background (AI), 3) foreign-born mothers from low-income countries (FB-LIC), 4) foreign-born mothers from lower-middle-income countries (FB-LMIC), 5) foreign-born mothers from upper-middle-income countries (FB-UMIC), and 6) foreign-born mothers from high-income countries (FB-HIC). Countries' income groups were determined using the United Nations, World Health Organization and World Bank country listings [27-31] and income groups were categorized according to gross national income per capita in 2017. Income brackets and thresholds for gross national income per capita were $<$ US $\$ 1005$ for low-income, US\$1006-3955 for lower-middle-income, US\$3956-12,235 for upper- 
middle-income, and > US $\$ 12,235$ for high-income [32]. Low and middle-income country groups as per the World Bank categorization are listed in Additional file 1: Table S1; high-income economies included the major migrant groups to Australia such as those from the UK and New Zealand (Additional file 2: Table S2).

The Australian Bureau of Statistics produces the Socio-Economic Indexes for Areas (SEIFA) score, which ranks areas in Australia according to relative socio-economic advantage and disadvantage from information collected during the Australian Census [33]. We specifically used the Index of Relative Socio-economic Advantage and Disadvantage (IRSAD), an index that summarises the information about the economic and social conditions of people and households within a census district [33]. This index includes measures of relative advantage and disadvantage; with scores of 1 representing the lowest score (relative lack of disadvantage) on the index and 10 the highest score of the index (greatest disadvantage). IRSAD scores were grouped into six categories: advantaged ( $90 \%$ of the IRSAD score), least disadvantaged $(76-90 \%$ of the IRSAD score),less disadvantaged (51-75\% of the IRSAD score), little disadvantage (25-50\% of the IRSAD score), more disadvantage (10-25\% of the IRSAD score), and the most disadvantaged (lowest 10\%) areas of WA [33]. We used the IRSAD score for the census district where the mother was living at the time of birth [33].

\section{Child variables}

Infant variables were gender, gestational age, proportion of optimal birth weight (POBW) and Apgar score at 5 min. The adverse fetal outcomes were: (i) preterm birth, (ii) IUGR and (iii) low Apgar score. Preterm birth was determined using a final gestational age variable that was categorized into seven groups of gestation: extreme preterm ( $<28$ weeks), very early preterm ( $28-31$ weeks), early preterm (32-33 weeks), late preterm (34-36 weeks), early term (37-38 weeks), full term (39-41 weeks), and post term ( $\geq 42$ weeks). Any pre-term was defined as $<37$ weeks and the category of full term birth (39-41 weeks) was used as the reference group for the multinomial regression data analysis. IUGR was determined using the POBW, which is the ratio of observed birth weight to optimal birth weight, and is a variable that is calculated and provided to researchers by the data custodians in WA.

The algorithm from which the optimal birth weight is calculated was developed from a regression model accounting for non-pathological causes of fetal size (gestational age, maternal height, maternal parity and infant sex) in a total population of singleton births without any recorded risk factors for intrauterine growth restriction such as maternal smoking $[34,35]$. The percentage was categorized into seven groups: $<75 \%, 75-84 \%$, $85-$ $94 \%, 95-104 \%, 105-114 \%, 115-124$, and $>125 \%$ with < $75 \%$ considered as severe, $75-84 \%$ as moderate and $85-$ $94 \%$ as mild growth restriction. The middle group, $95-$ $104 \%$ was used as the reference group in the multinomial regression data analysis [35]. The reference group comprised almost one third (32.1\%) of the total population; POBW less than $85 \%$ was equivalent to approximately less than the 10th percentile of optimal birth weight [36] and POBW greater than $115 \%$ was equivalent to greater than the 90th percentile of optimal birth weight. Apgar score was determined using the Apgar variable at $5 \mathrm{~min}$ and the categories were defined as normal (7 to 10 ), fairly low (4 to 6 ) and critically low (3 or less), with the normal group being used as the reference group in the analysis. Apgar score at $1 \mathrm{~min}$ was excluded from analyses due to inadequate reporting or missing data.

\section{Analyses}

Descriptive statistics were used to summarise the characteristics of the study participants. Multinomial logistic regression models were used to estimate the risk of pre/ post term birth relative to full term birth among $\mathrm{MCB}$ groups compared to Australian-born women of non-Indigenous background, after adjusting for potential confounders including maternal age, SEIFA score, parity, birth year and child's sex. The model was also used for assessing the risk of suboptimal (POBW less than 95\% or more than 104\%) relative to optimal (POBW between 95 and 104\%) birth weight and risk of low relative to normal Apgar score. Both crude and adjusted relative risk ratios, and their $95 \%$ confidence interval values were reported. Missing data were considered missing at random and complete case analysis was used. Since smoking data were only available from September 1997, we conducted regression analysis separately for the twotime periods: 1980-1997 (without adjusting for smoking) and 1997-2010 (with adjusting for smoking). All analyses were performed using STATA version 14 (StataCorp LP, College Station, TX, USA).

\section{Results}

For the years 1980 to 2010 our study included 769,695 singleton births with a valid MCB (out of a total 792,373 WA births during that period) of which $66.2 \%$ were children of ANI mothers, $19.0 \%$ were children of FB-HIC mothers, $5.8 \%$ were children of $\mathrm{AI}$ mothers, $4.3 \%$ were children of FB-LMIC mothers, $4.1 \%$ were children of FB-UMIC, and $0.6 \%$ were children of FB-LIC. Only $0.1 \%$ of our sample population had missing data for MCB. Socio-demographic factors including smoking status are presented in Table 1. AI mothers were more likely to be aged less than 20 years (27.2\%) compared to ANI 
Table 1 Characteristics of the study population (singleton births from 1980 to 2010 in WA) and their mothers by maternal country of birth group

\begin{tabular}{|c|c|c|c|c|c|c|c|}
\hline & $\begin{array}{l}\text { ANI } \\
(n=509,589)\end{array}$ & $\begin{array}{l}\mathrm{Al} \\
(n=44,820)\end{array}$ & $\begin{array}{l}\text { FB-LIC } \\
(n=4458)\end{array}$ & $\begin{array}{l}\text { FB-LMIC } \\
(n=33,315)\end{array}$ & $\begin{array}{l}\text { FB-UMIC } \\
(n=31,254)\end{array}$ & $\begin{array}{l}\text { FB-HIC } \\
(n=146,259)\end{array}$ & $\begin{array}{l}\text { Total } \\
(n=769,695)\end{array}$ \\
\hline \multicolumn{8}{|l|}{ Gender } \\
\hline Female & $248,116(48.7)$ & $21,868(48.8)$ & $2175(48.8)$ & $16,076(48.3)$ & $15,038(48.1)$ & $71,344(48.8)$ & $374,617(48.7)$ \\
\hline Male & $261,455(51.3)$ & $22,943(51.2)$ & $2282(51.2)$ & $17,238(51.7)$ & $16,212(51.9)$ & $74,909(51.2)$ & $395,039(51.3)$ \\
\hline Total & $509,571(100)$ & $44,811(100)$ & $4457(100)$ & $33,314(100)$ & $31,250(100)$ & $146,253(100)$ & $769,656(100)$ \\
\hline
\end{tabular}

Pearson chi2 (5) 7.1953, $\operatorname{Pr}=0.207$

Maternal age

$\begin{array}{llllllll}<20 \text { years } & 28,763(5.6) & 12,179(27.2) & 118(2.7) & 629(1.9) & 675(2.2) & 4587(3.1) & 46,951(6.1) \\ \text { 20-24 years } & 107,752(21.2) & 15,375(34.3) & 777(17.4) & 4831(14.5) & 4331(13.9) & 23,496(16.1) & 156,562(20.3) \\ \text { 25-29years } & 175,640(34.5) & 10,012(22.3) & 1438(32.3) & 11,006(33.0) & 9505(30.4) & 45,334(31.0) & 252,935(32.9) \\ \text { 30-34 years } & 137,957(27.1) & 5032(11.2) & 1300(29.2) & 10,661(32.0) & 10,360(33.2) & 46,067(31.5) & 211,377(27.5) \\ 35-39 \text { years } & 51,455(10.1) & 1877(4.2) & 682(15.3) & 5155(15.5) & 5276(16.9) & 22,379(15.3) & 86,824(11.3) \\ >39 \text { years } & 8009(1.6) & 345(0.8) & 143(3.2) & 1033(3.1) & 1106(3.5) & 4395(3.0) & 15,031(2.0) \\ \text { Total } & 509,576(100) & 44,820(100) & 4458(100) & 33,315(100) & 31,253(100) & 146,258(100) & 769,680(100)\end{array}$

Pearson chi2 (25) $6.0 \times 10^{+4} \operatorname{Pr}<0.001$

Marital status

$\begin{array}{ll}\text { Never married } & 43,661(8.6) \\ \text { Widowed } & 335(0.07) \\ \text { Divorced } & 1812(0.4) \\ \text { Separated } & 3620(0.7) \\ \text { Married } & 459,242(90.1) \\ \text { Unknown } & 919(0.2) \\ \text { Total } & 509,589(100)\end{array}$

$78(0.2)$

$95(0.2)$

$6821.5)$

$28,167(62.8)$

$316(0.7)$

$44,820(100)$

$239(5.4)$

$10(0.4)$

$1318(4)$

$50(0.2)$

$18(0.4)$

$91(0.3)$

$84(1.9)$

$251(0.8)$

$4089(91.7)$

$31,491(94.5)$

$18(0.4)$

$114(0.3)$

$4458(100)$

$33,315(100)$

Pearson chi2 (25) $4.1 \times 10^{+4} \operatorname{Pr}<0.001$

SEIFA score

$\begin{array}{ll}0-10 & 44,509(9.9) \\ 11-25 & 74,190(16.5) \\ 26-50 & 116,710(26) \\ 51-75 & 113,336(25.2) \\ 76-90 & 63,480(14.1) \\ >90 & 37,467(8.3) \\ \text { Total } & 449,692(100)\end{array}$

Pearson chi2 (25) $3.1 \times 10^{+4} \operatorname{Pr}<0.001$

Parity

$\begin{array}{ll}0 & 210,158(41.5) \\ 1 & 171,955(40) \\ 2 & 83,577(16.5) \\ 3 & 28,546(5.6) \\ 4 & 8980(1.8) \\ 5 \text { \& more } & 3044(0.6) \\ \text { Total } & 506,260(100)\end{array}$

Pearson chi2 (25) $2.2 \times 10^{+4} \operatorname{Pr}<0.001$

Smoking

Yes

$42,866(18.3)$

$10,892(50.7)$

$\begin{array}{ll}535(12.9) & 4071(13.3) \\ 762(18.5) & 5000(16.3) \\ 1169(28.4) & 7965(26) \\ 868(21.1) & 7292(23.8) \\ 490(11.9) & 3881(12.7) \\ 295(7.2) & 2450(8) \\ 4119(100) & 30,659(100)\end{array}$

$2582(8.9)$

3933 (13.6)

$6912(23.9)$

$7535(26)$

4802 (16.6)

$3174(11)$

$28,938(100)$

$10,895(8.2)$

$19,911(15)$

$33,416(25.1)$

$34,856(26.2)$

$21,121(15.9)$

$12,901(9.7)$

$133,100(100)$

$35,829(100)$

$13,122(30.7)$

$1360(31.8)$

$13,932(42.2)$

$11,375(34.4)$

8097 (19)

1267 (29.6)

$4999(15.1)$

5585 (11.1)

763 (17.8)

$1830(5.5)$

$3466(8.1)$

467 (11)

667 (2.0)

$249(0.8)$

$42,696(100)$

$157(3.7)$

$4283(100)$

$33,052(100)$
$12,725(41)$

10,998 (35.4)

4908 (15.8)

$1611(5.2)$

573 (2)

218 (0.7)

$31,033(100)$
$57,523(39.6)$

$50,008(34.5)$

24,633 (17)

8978 (6.25)

2955 (2)

$1057(0.7)$

$145,154(100)$
70,688 (9.2)

$576(0.07)$

$2719(0.4)$

$5821(0.8)$

688,142 (89.4)

$1749(0.2)$

$769,695(100)$

75,144 (11)

$112,487(16.5)$

$174,313(25.6)$

168,636 (24.7)

95,149 (13.9)

$56,608(8.3)$

682,337 (100)

$308,820(40.5)$ 255,995 (33.6)

126,977 (16.7)

47,017 (6.2)

$16,910(2.2)$

6759 (0.9)

$762,478(100)$ 
Table 1 Characteristics of the study population (singleton births from 1980 to 2010 in WA) and their mothers by maternal country of birth group (Continued)

\begin{tabular}{|c|c|c|c|c|c|c|c|}
\hline & $\begin{array}{l}\text { ANI } \\
(n=509,589)\end{array}$ & $\begin{array}{l}\mathrm{Al} \\
(n=44,820)\end{array}$ & $\begin{array}{l}\text { FB-LIC } \\
(n=4458)\end{array}$ & $\begin{array}{l}\text { FB-LMIC } \\
(n=33,315)\end{array}$ & $\begin{array}{l}\text { FB-UMIC } \\
(n=31,254)\end{array}$ & $\begin{array}{l}\text { FB-HIC } \\
(n=146,259)\end{array}$ & $\begin{array}{l}\text { Total } \\
(n=769,695) \\
\end{array}$ \\
\hline No & $191,678(81.7)$ & $10,603(49.3)$ & $3023(98.1)$ & $17,660(97.2)$ & $16,617(94.4)$ & $47,642(84.8)$ & $287,223(81.8)$ \\
\hline Total & $234,544(100)$ & $21,495(100)$ & $3081(100)$ & $18,167(100)$ & $17,651(100)$ & $56,185(100)$ & $351,123(100)$ \\
\hline \multicolumn{8}{|c|}{ Pearson chi2 (25) $2.1 \times 10^{+4} \operatorname{Pr}<0.001$} \\
\hline
\end{tabular}

mothers and foreign mothers, whilst FB-LMIC mothers were less likely to be aged less than 20 years of age than ANI mothers (1.9 vs 5.6\%). FB-UMIC mothers were more likely to be married (96.0\%) followed by FB-LMIC (94.5\%), FB-HIC (92.4\%) and FB-LIC (91.7\%) compared with ANI mothers (90.1\%) and AI mothers (62.8\%). As shown in Table 1 AI mothers had the lowest (0-2) and highest (3-5) parity scores, whilst FB-LIC mothers had lower parity levels (parity $0-2,31.8,29.6$ and $17.8 \%$ respectively) compared to ANI mothers (parity 0-2, 41.5, 40 and $16.5 \%$ respectively). Yet compared to ANI and other foreign-born, FB-LIC mothers had the second highest parity levels (3, 4, and 5) after AI mothers. Only $13.3 \%$ of FB-LMIC and $12.9 \%$ FB-LIC mothers were categorised as most disadvantaged, in comparison to AI mothers of whom $35.0 \%$ were categorised as such. Smoking was least prevalent in foreign-born, particularly FB-LIC (1.9\%), FB-LMIC (2.8\%), FB-UMIC (5.9\%) respectively, compared with mothers in the other groups (AI 50.7\% and ANI 18.3\%). The prevalence of preterm birth (<37 weeks) increased from $6.6 \%$ in 1980 to $7.6 \%$ in 2010 and with an average $7.2 \%$ over the whole-time period (Fig. 1), whilst post term births decreased over time (Fig. 2).

Perinatal outcomes (preterm birth, IUGR and Apgar scores) in relation to maternal country of birth are presented in Tables 2, 3, 4, 5, 6 and 7 respectively.

For the period from 1980 to 1996, children of FB-LIC mothers had a non-significantly increased risk of preterm birth compared to those of ANI mothers (extreme preterm adjusted relative risk ratio [aRRR] 1.59, 95\% confidence interval $[\mathrm{CI}] 0.87,2.89$; very early preterm aRRR 1.63, 95\% CI 0.92, 2.89). During this period children of FB-LMIC mothers had a small but significantly increased risk of preterm and post-term births (late preterm aRRR $1.35,95 \%$ CI 1.25, 1.46; early term aRRR 1.42, 95\% CI 1.37,1.48; post-term aRRR 1.29, 95\% CI $1.01,1.64)$. Children of AI mothers had significantly increased risk in all categories of preterm and post term births during this period. For the period from 1997 to 2010, a non-significant increased risk of preterm and post-term births was observed for FB-LIC mothers (extreme preterm aRRR 1.42, 95\% CI 0.98, 2.04; very early preterm aRRR 1.37 , 95\% CI 0.92, 2.04; post-term

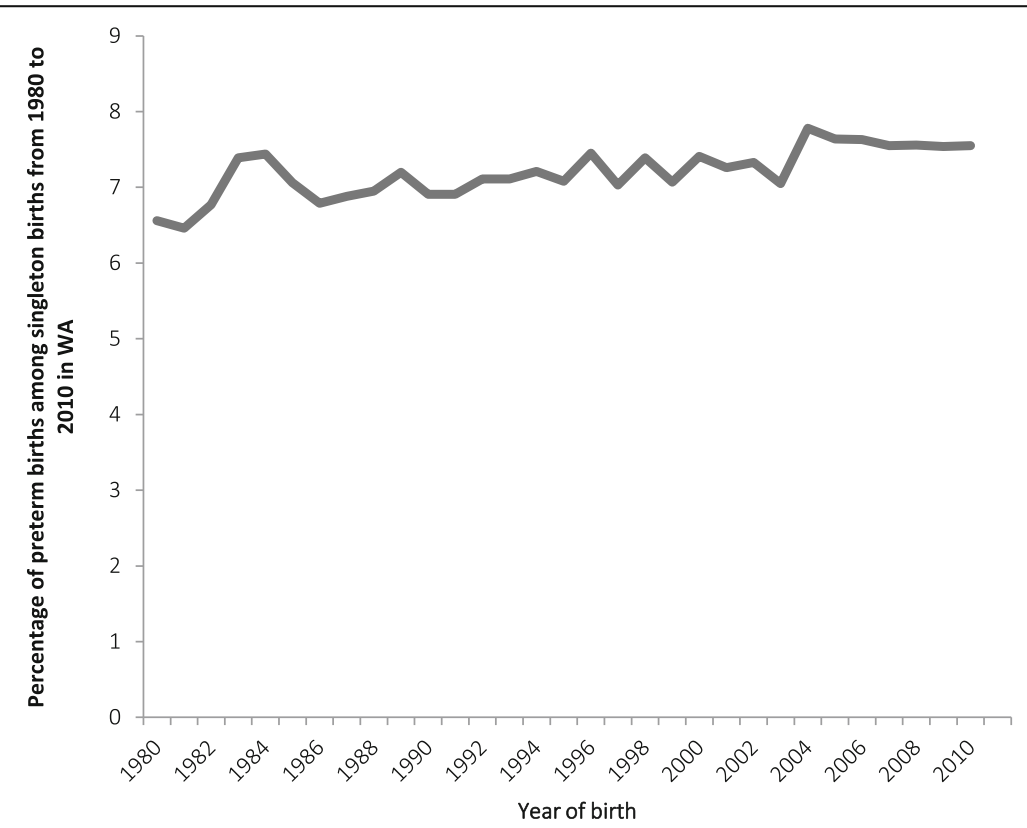

Fig. 1 Prevalence of preterm birth in singleton births from 1980 to 2010 in WA 


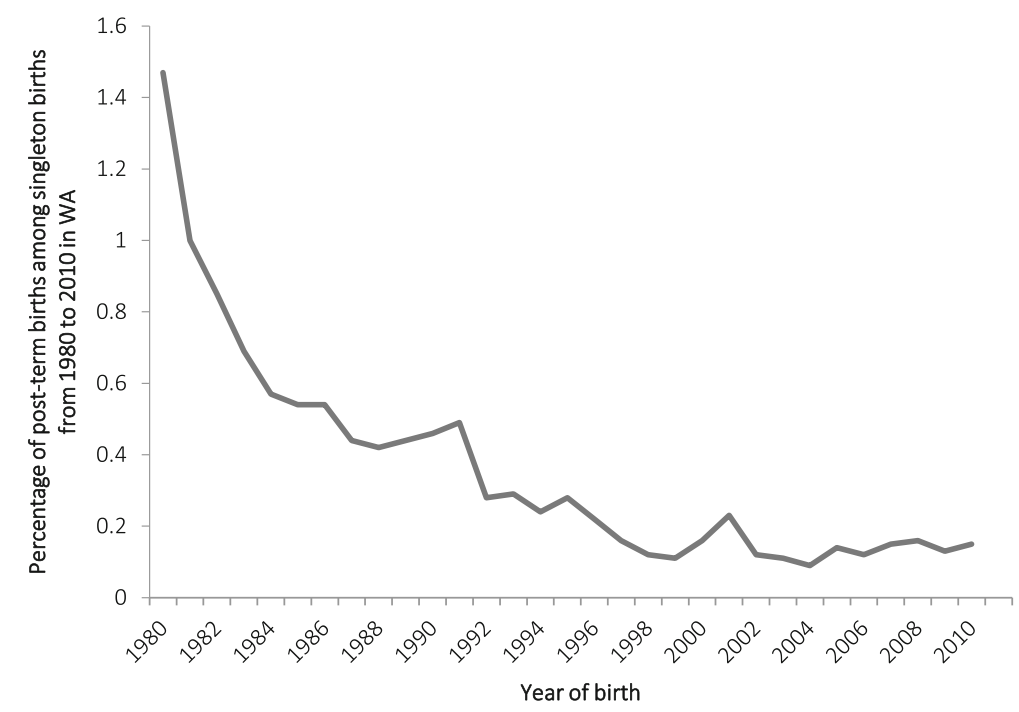

Fig. 2 Prevalence of post-term births in singleton births from 1980 to 2010 in WA

aRRR 1.93, 95 CI 0.99, 3.78). FB-LMIC mothers also had increased risks of extreme preterm (aRRR 1.32, 95\% CI $1.10,1.57)$ and very early preterm (aRRR 1.34, 95\% CI $1.11,1.62)$ births. Whilst a slight increased risk of latepreterm (aRRR 1.13, 95\% CI 1.04, 1.23) and early term births (aRRR 1.16, 95\% CI 1.11, 1.21) was seen in children of FB-UMIC during the first period and an only slightly increased risk of early term in the second period, children of FB-HIC had only a very slight increased risk of late preterm birth during the first period (aRRR 1.07, 95\% CI 1.03, 1.11).

Children of AI mothers had increased risk of severe IUGR and increased risk of excessive fetal growth during the period from 1980 to 1996 (Table 4). There was a slight increase in risk of mild growth restriction for children of FB-LIC mothers (aRRR 1.17, 95\% CI 1.00, 1.36), and also a slightly elevated risk of mild (aRRR 1.08, 95\% CI 1.03, 1.13) and moderate IUGR (aRRR 1.15, 95\% CI $1.08,1.23)$ for children of FB-LMIC mothers. IUGR was more evident in children of AI and in those of foreignborn women from low and lower middle-income countries during the second period (1997-2010) of this study (Table 5). During this period for children of FB-LIC and FB-LMIC mothers, there were increases in severe (aRRR 1.69, 95\% CI 1.30, 2.20; aRRR 1.72, 95\% CI 1.53, 1.93), moderate (aRRR 1.54, 95\% CI 1.32, 1.81; aRRR 1.59, 95\% CI 1.48, 1.70) and mild (aRRR 1.28, 95\% CI 1.14, 1.43; aRRR $1.31,95 \%$ CI $1.25,1.38)$ IUGR compared to children of ANI mothers. Children of FB-UMIC mothers had increased risk of severe (aRRR 1.17, 95\% CI 1.03, 1.33), moderate (aRRR 1.28, 95\% CI 1.19,1.38) and mild (aRRR 1.14, 95\% CI 1.09,1.20) IUGR during the second period only (Table 5), whilst children of FB-HIC mothers had very slight increased risks of severe, moderate and mild IUGR during the first periods (Table 4).

Compared to children of ANI mothers, children of FB-LIC mothers had an increased adjusted relative risk of critically low 5-min Apgar score (1997-2000 aRRR $1.52,95 \%$ CI $1.08,2.15$ ) and an elevated risk of fairly low 5-min Apgar scores in the second period (aRRR 2.17, 95\% CI 1.65, 2.85) (Table 7). Again, increased risks were observed in critically low and fairly low Apgar scores at 5 min for children of AI mothers. However, FB-HIC mothers had a minimally increased risk of fairly low Apgar score in the first time period (Table 6).

\section{Discussion}

The proportion of foreign born women in our dataset was consistent with current data from the Australian Bureau of Statistics reporting 28\% of Australians are born overseas [33]. However we identified considerable variation in the distribution of demographic characteristics across our study groups. A higher proportion (27\%) of Australian-born Indigenous mothers were less than 20 years of age), while Australian-born non-Indigenous and foreign-born mothers were more likely to be married (90.1 to $93.2 \%$ compared $62.8 \%$ of Australianborn Indigenous mothers). Over a third of Australianborn Indigenous mothers were in the most socio-economically disadvantaged category as were $13.3 \%$ of FBLMIC and $12.9 \%$ of FB-LIC mothers compared to only 9.9\% of ANI mothers, whilst smoking during pregnancy was most prevalent in Australian-born Indigenous mothers and least prevalent in foreign-born mothers. Although foreign-born women from countries of low and middle income accounted for $9 \%$ of the Western 


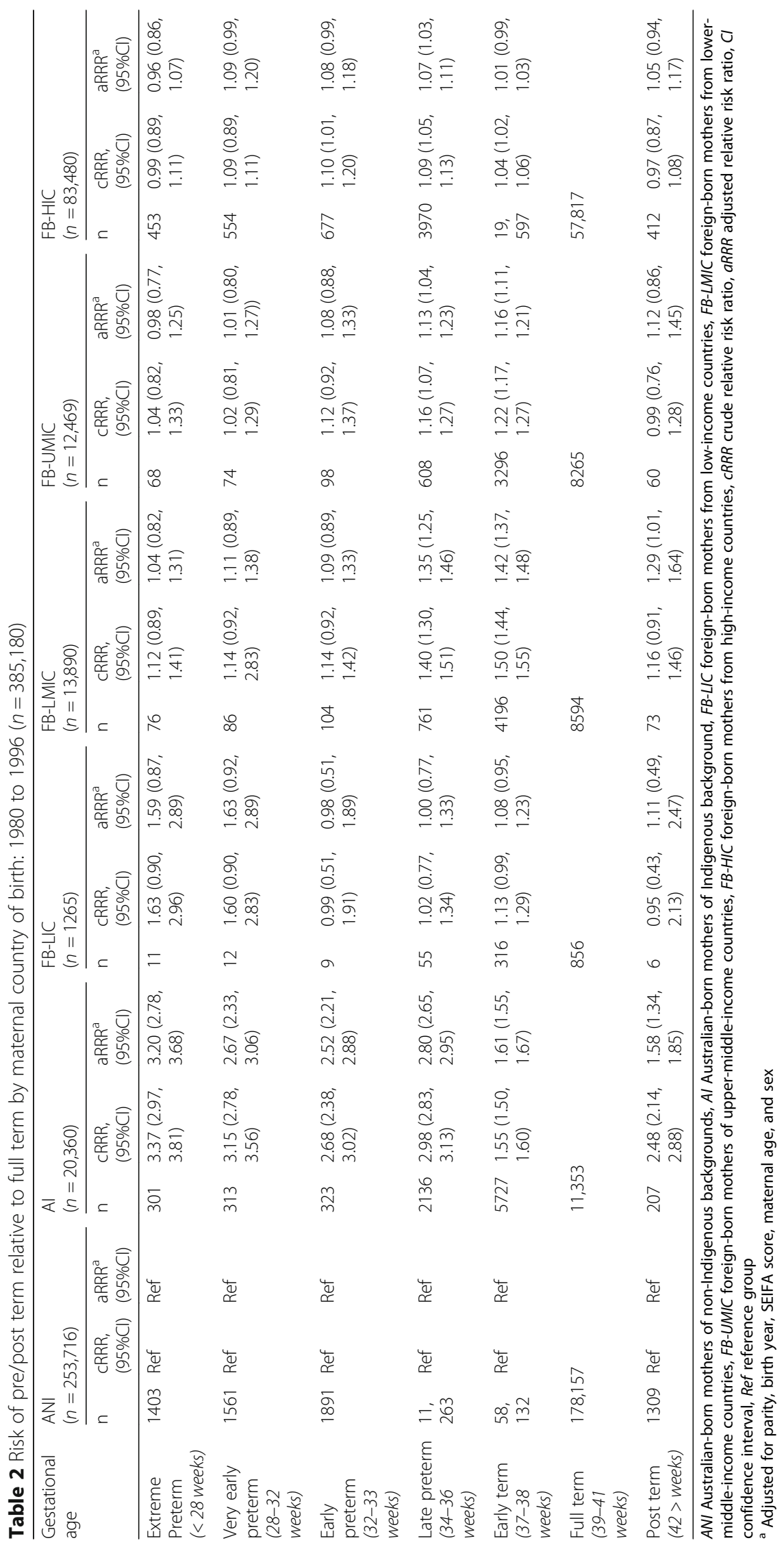




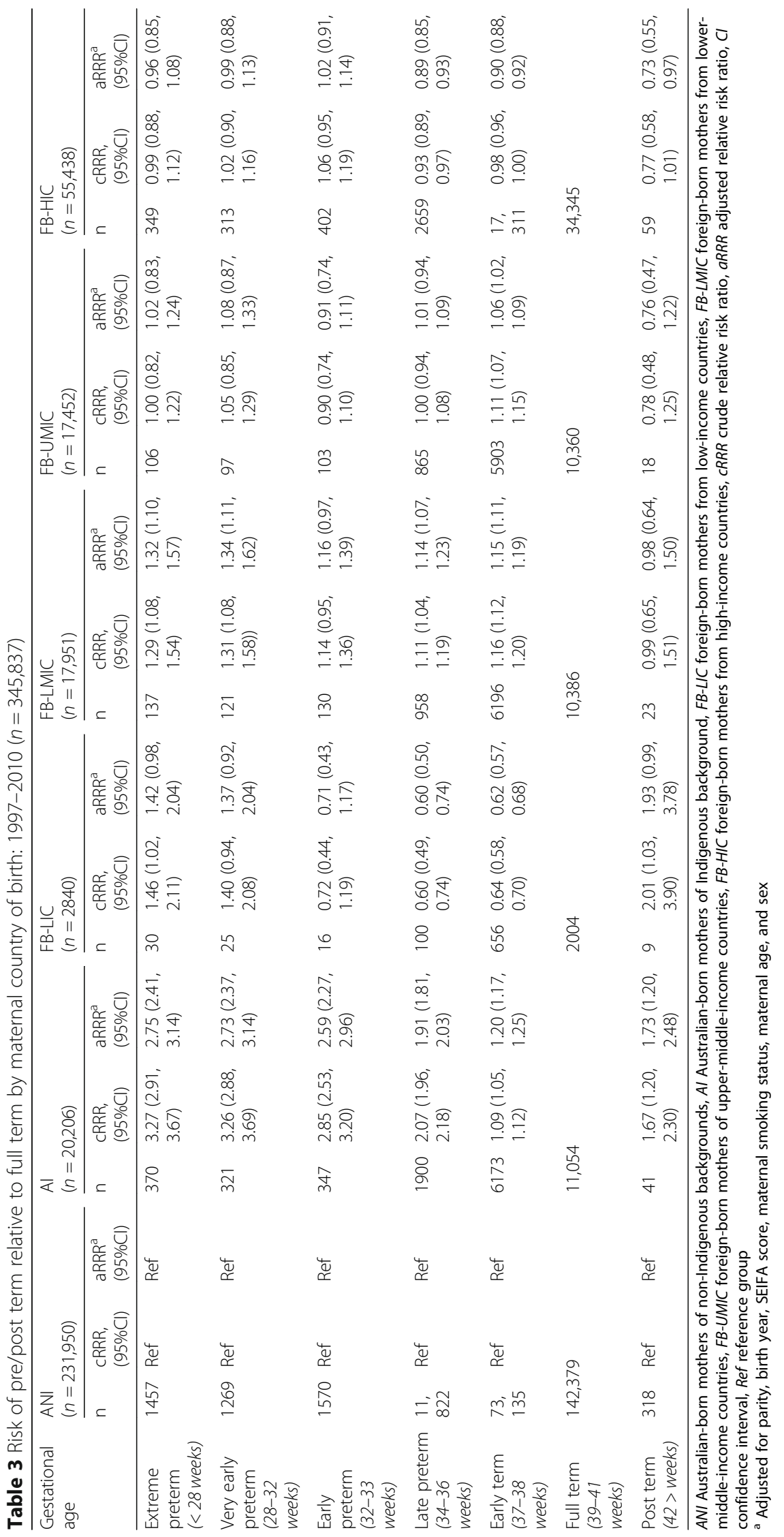




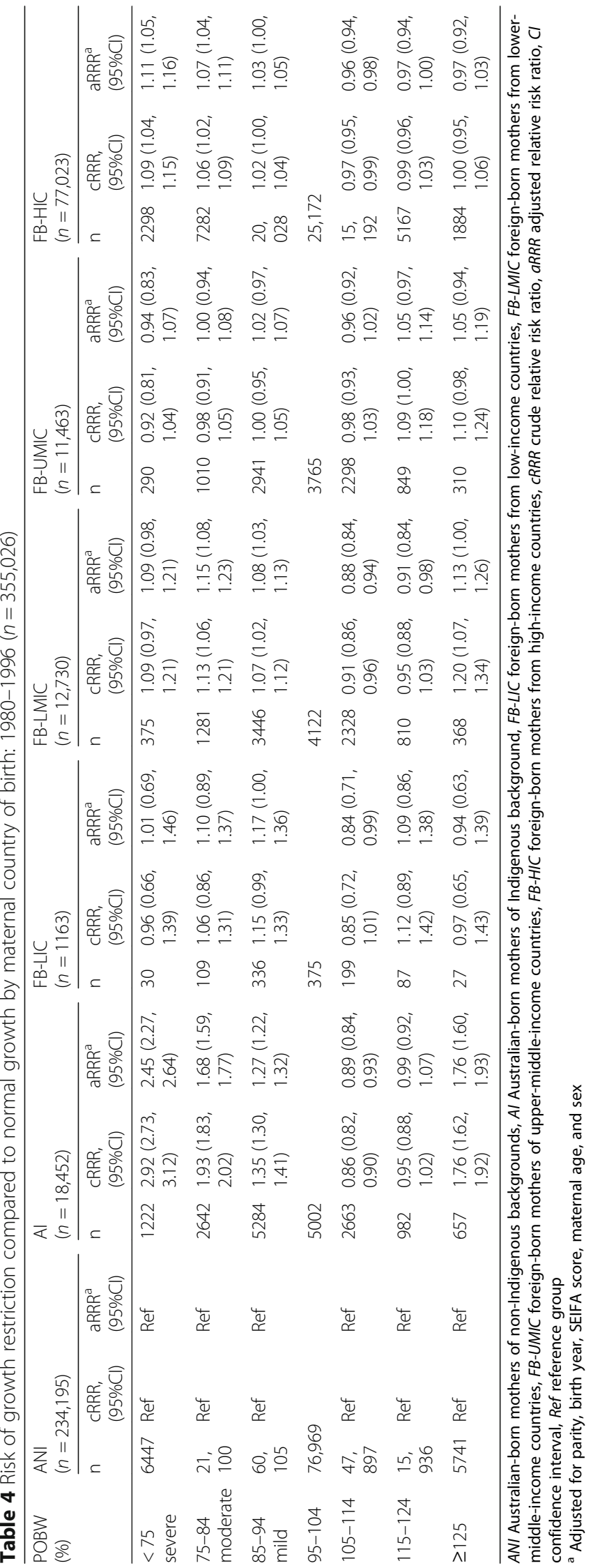




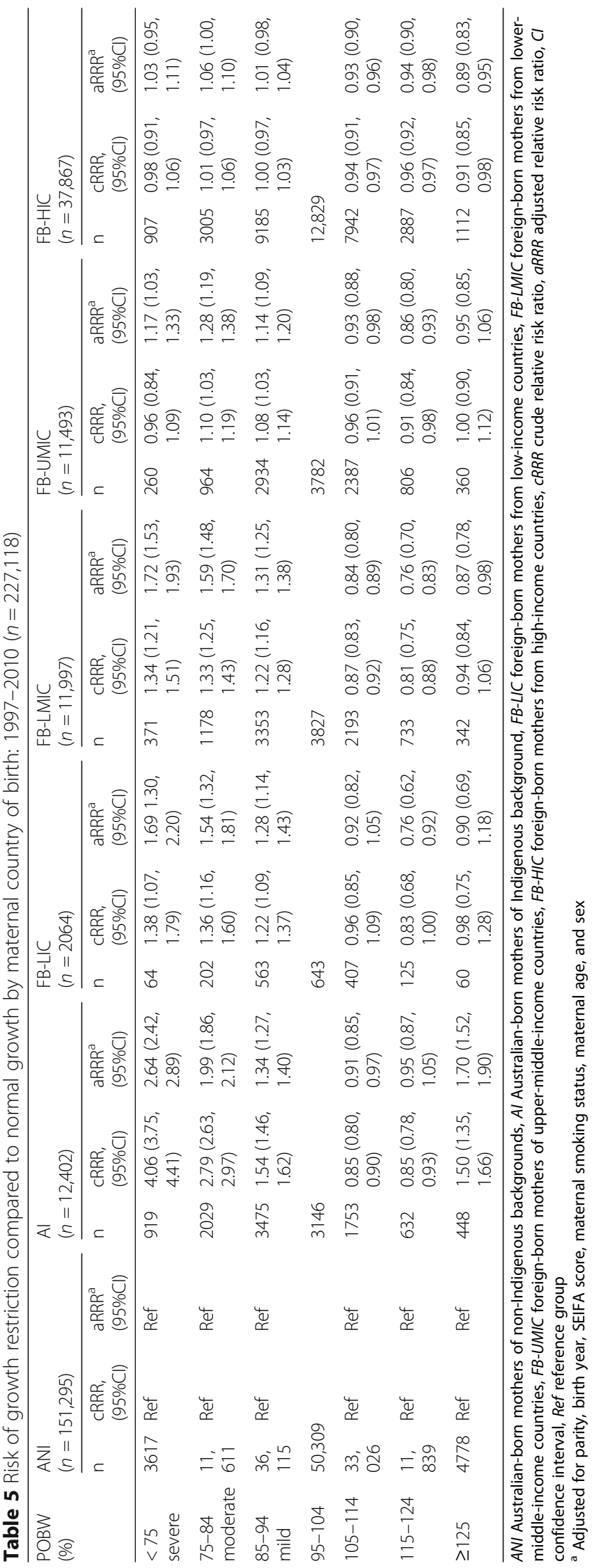




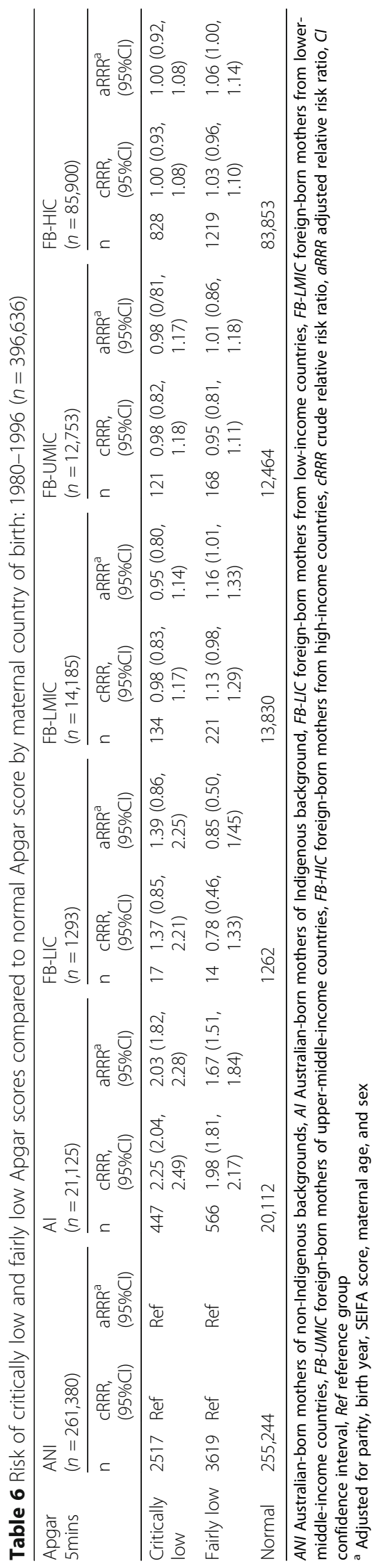




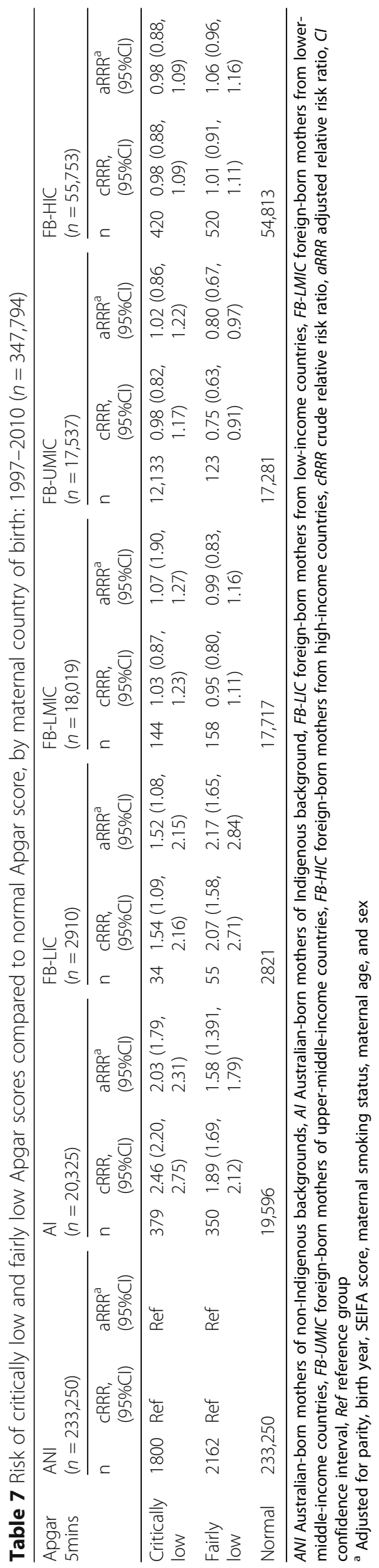


Australian childbearing population and these mothers were more likely to be older and married, their infants may have been at some increased risk of extreme prematurity $(<28$ weeks), very early preterm birth $(28-32$ weeks), late preterm birth (34-36 weeks), early term (37-38 weeks) and post term (42> weeks), as well as IUGR (severe, moderate and mild) for one or both of the time periods. However it is important to be cautious about the strength of this evidence particularly in relation to preterm birth given the extremely small sample sizes in some of these groups and the associated wide confidence intervals. Furthermore, children of foreignborn low income mothers also did have an increased risks of both critically low and fairly low 5-min Apgar scores and the evidence for this was stronger than for some of the preterm birth categories. However these poorer perinatal and neonatal outcomes were not seen in children of foreign-born mothers from high-income countries, whose better outcomes mirrored our comparative group (children of Australian-born non-Indigenous mothers). Preterm birth rates have increased worldwide [3] but in WA the rate has been relatively stable between 1980 and 2010 and with an average of $7.2 \%$ children each year born prematurely (Fig. 1), whilst post term births decreased over time (Fig. 2).

Our findings of an increased risk of adverse infant outcomes for Indigenous mothers are consistent with our previous analyses [36] and previous literature which has found that IUGR [37, 38] and low birth weight [39] are more prevalent in this population. The underlying causes for these disparities are believed to be multiple, extending from specific risk factors, such as maternal smoking and medical conditions, to more complex societal issues related to social disadvantage [40].

The strengths of this study include the use of population-based data over a 30-year period from the WA Data linkage system. This infrastructure has been very effective in linking data from national and local health and welfare data sets and has been a cost effective way of improving health policy and practice [41]. Another strength is the use of POBW, which is superior to weight $\mathrm{z}$ scores and percentiles (which only compare a given birthweight with the average birthweight for all sex-specific births at the same gestational age) because it relates to the average birthweight for live births with the same sex, maternal age, maternal height, and maternal parity, and without any known risk factors (such as smoking) for pre-term birth or adverse birth outcomes [34, 35]. Moreover, the model from which it has been derived has also been validated against fetal weights estimated from serial biometric ultrasound scans at least for infants over 29 weeks' gestation [42].

In our dataset we were unable to adjust for maternal medical conditions and pregnancy complications, as the data were incomplete for these variables. Furthermore, the population sources do not include detailed information on maternal education and other important maternal variables such as weight, nutrition, lived trauma and adverse child experiences, which could have provided a fuller picture. As such, our data were limited to maternal country of birth as the only indicator of immigration status. Further data such as age of arrival into Australia and immigration status would also have been valuable and remains a limitation in immigrant and refugee identification for this study [43].

An increased risk of adverse pregnancy and birth outcomes among foreign-born women compared to nativeborn women in our study has also been demonstrated in several other studies [11, 13, 16, 18, 19, 44]. A 2012 Danish study found that foreign-born women had increased risk of having a baby small for gestational age, with the highest risk observed among mothers from Lebanon, Somalia, and Pakistan [16] countries which we would have classified as 'low and middle income'. In the same study children of foreign-born mothers were more likely to be born very preterm ( $<33$ weeks) or moderately preterm (33-36 weeks) [16]. In contrast to our study, these data included detailed immigration information such as length of residence in Denmark, age at immigration and immigration status but relationships between these variables and the child's birth outcomes were not found [16]. A Canadian study reported higher rates of caesarean sections in women from Latin America, the Caribbean and Sub-Saharan Africa compared to Canadian-born women, but in contrast to our study, they showed a lower risk of preterm delivery, findings the authors postulated might be associated with a healthy migrant effect [13]. However, this study also reported a three-fold increase risk of low birth weight compared with those of Canadian-born women. We elected to investigate IUGR rather than birth weight because IUGR is a better predictor of poorer birth outcomes as it refers to deviation and reduction in the expected fetal growth during pregnancy [5]. A recent US study also found that foreign-born non-Hispanic black women had significantly lower rates of preterm birth and small for gestational age in comparison to US-born nonHispanic black women [15]. There were also significantly lower rates of preterm birth and intra-uterine growth restriction among black women from Sub-Saharan Africa compared to native Caribbean-born black women [15]. Authors of a Swedish cohort study suggested that an increase in preterm birth in foreign-born women could be the result of the stress experienced during migration and the fact that female refugees of child-bearing age are more likely to be victims of trauma, traumatic events, acts of violence and thus more vulnerable to stress exposure [44].

An Australian study investigating how antenatal and perinatal characteristics compared between children 
diagnosed with ID, those diagnosed with ASD and those diagnosed with ASD and ID, found that any category of preterm birth was associated with a two-fold increased risk of mild and severe ID [8]. Another data linkage study with clinical cases linked to midwives data in New South Wales, Australia, found that having a mother born outside of Australia was one of four risk factors which increased the likelihood of a subsequent autism diagnosis [45]. Our findings of prematurity and foreign-born mothers, shows that children of immigrant backgrounds are at an increased risk of the subsequent development of neurodevelopmental disabilities such as ASD, as previously found [45].

IUGR was an outcome in our study associated consistently across the two time periods with an increased risk for infants born to foreign women from low to middle income countries. Its presence has also been linked to the subsequent development of neurodevelopmental disabilities [36]. Poor fetal growth can be determined by measuring POBW and, when compromised, has been shown in one WA study to be strongly associated with an increased risk of mild to moderate ID, severe ID and ASD associated with ID but not ASD without ID [8]. An earlier WA study also found that severe IUGR (POBW $<75)$ was associated with a threefold increased risk in severe ID [36]. Also, a child with POBW of less than $85 \%$ was two to three times more likely to be diagnosed with mild to moderate ID compared to a child with POBW of 95 to 104\% (normal POBW), and this likelihood increased to more than four times for severe ID [8]. Severe IUGR was associated with four times the risk for severe ID, and also more than three times the risk for ASD with ID [8]. These associations of IUGR with ASD and ID are concerning because of our findings that children of foreign-born women from low and middle-income countries are at increased risk of IUGR and hence of such neurodevelopmental disabilities and disorders.

The American Academy of Paediatrics states that in predicting outcomes, a $5 \mathrm{~min}$ Apgar score of 0 to 3 correlates with neonatal mortality in large populations but does not predict future neurologic dysfunction [7]. In contrast a low 5 min Apgar score has been shown to increase the risk of cerebral palsy, with 20 to 100 times the risk compared to $5 \mathrm{~min}$ Apgar scores from 7 to 10 [7]. A Scottish study found that a low Apgar score at 5 min was strongly associated with the risk of neonatal and infant death [6]. Our study found children of foreign-born women from low and middle-income countries had an increased risk of critically low (0 to 3 ) and fairly low (4 to 6) Apgar scores, particularly after adjustment for birth year, gender, maternal age, SEIFA score, parity and smoking.

Our findings illustrate the vulnerabilities of children born to foreign women from low and middle-income countries. Our findings show that for some time periods pregnancy and birth outcomes can be influenced by maternal country of birth, especially if mothers come from low and middle-income countries where they could have been exposed to factors such as war, trauma, poverty, and limited opportunities for education and lack of access to proper healthcare. The higher perinatal risk observed in the second period of this study, 1997 to 2010 perhaps demonstrates the changing dynamics of foreign-born populations arriving in Australia from low and middle-income countries. Clinically these results illustrate the need for ongoing monitoring and targeting of foreign-born women during their antenatal care to reduce risks of adverse pregnancy and birth outcomes. A US study suggested that the patterns of prematurity, mortality, and small for gestational age experienced by infants of immigrant women, can lead to an increased risk of long term medical, developmental, and economic disadvantage for children and their families [15].

\section{Conclusion}

This study determined that children of foreign-born women from low and middle-income countries had a greater risk of preterm and post term birth, intra uterine growth restriction and lower Apgar scores compared to children of Australian-born non-Indigenous mothers. These results indicate the need for strategies that could be implemented to address immigrant health, particularly targeting antenatal care in order to reduce risks of poor pregnancy, neonatal, and birth outcomes. Policy makers also need to implement more culturally sensitive strategies to provide services to these groups of families. Highlighting and addressing multicultural issues could improve these outcomes and the cultural needs of immigrant women by medical and allied health care providers.

\section{Additional files}

Additional file 1: Table S1. Low and middle-income countries. (PDF $251 \mathrm{~kb})$

Additional file 2: Table S2. High income countries. (PDF 243 kb)

\section{Abbreviations}

Al: Australian-born mothers of indigenous background (Aboriginal and Torres Strait Islander); ANI: Australian-born mothers of non-indigenous backgrounds (Caucasian); ASD: Autism Spectrum Disorders; CALD: Culturally and

linguistically diverse backgrounds; CP: Cerebral Palsy; FB-HIC: Foreign-born mothers from high income countries; FB-LIC: Foreign-born mothers from low income countries; FB-LMIC: Foreign-born mothers from lower middle-income countries; FB-UMIC: Foreign-born mothers from upper middle-income countries; ID: Intellectual Disability; IRSAD: Index of Relative Socio-economic Advantage and Disadvantage; IUGR: Intra uterine growth restriction; MCB: Maternal country of birth; POBW: Proportion of optimal birth weight; SEIFA: Socio-Economic Indexes for Areas; WA: Western Australian

\section{Acknowledgements}

The primary author was a receiptant of an Australian Government Research Training Program Scholarship at the University of Western Australia and 
would like to thank the Australian Government Research Training Program and the Developmental Pathways Project at Telethon Kids Institute, Perth Western Australia, for their support and funding of this study and her Ph.D. The authors have no competing interests to declare.

\section{Authors' contributions}

This research was undertaken as part of the primary author's (IA) PhD project. IA initiated and designed the research, analysed and interpreted the data, and wrote the manuscript. HL supervised, designed the research, helped analyse the data and contributed to the manuscript editing, revisions and review. SC and RM supervised and gave clinical advice and research direction to the study and contributed to manuscript editing, revisions and review. EG and JD supervised and developed the study and gave data linkage advice and manuscript editing, revisions and review. NdK supervised and designed the research and gave statistical advice on methods, data analysis and interpretation. KW gave statistical advice on methods, data analysis and interpretation and manuscript review. All authors have critically reviewed the manuscript and approved of the final version as submitted.

\section{Funding}

This research was undertaken while the author (IA) was in receipt of an Australian Governments Research Training Scholarship at the University of Western Australia (2017) and the Developmental Pathways Project Telethon Kids Institute Scholarship (2015-2016).

The National Health and Medical Research Council supported this project: Program Grant \#572742, NHMRC Senior Research Fellowship \# 1117105 (HL). The funding bodies had no role in the design of the study, data collection and analysis and the drafting of the manuscript.

\section{Availability of data and materials}

Our ethical approval does not allow for sharing of unpublished data. If such data were required an application would need to be made to the WA Department of Health Human Research Ethics Committee.

\section{Ethics approval and consent to participate}

Ethics approval for this study was obtained from the WA Department of Health Human Research Ethics committee (2011/64) and the University of Western Australia Human Research Ethics committee (RA/4/1/8074). Since routinely collected deidentified data were used for the analysis, individual written or informed consent was not considered necessary.

\section{Consent for publication}

Not applicable.

\section{Competing interests}

The authors declare that they have no competing interests.

\section{Author details}

${ }^{1}$ Telethon Kids Institute, The University of Western Australia, PO Box 855, West Perth, WA 6872, Australia. ${ }^{2}$ School of Paediatrics and Child Health, The University of Western Australia, Perth, WA, Australia. ${ }^{3}$ Department of General Paediatrics, Perth Children's Hospital, Perth, WA, Australia. ${ }^{4}$ School of Physiotherapy and Exercise Science, Curtin University, Perth, WA, Australia.

Received: 24 October 2017 Accepted: 29 July 2019

Published online: 09 August 2019

\section{References}

1. Srinivasjois R, Slimings C, Einarsdottir K, Burgner D, Leonard H. Association of gestational age at birth with reasons for subsequent hospitalisation: 18 years follow up in a Western Australian population study. PLoS One. 2015; 10:1-11.

2. Beck S, Wojdyla D, Say L, Betran A, Merialdi M, Requejo J, Rubens C, Menon $R$, Look P. The worldwide incidence of preterm birth: a systematic review of maternal mortality and morbidity. Bull World Health Organ. 2010;88(1):31-8.

3. Goldenberg R, Culhane J, Lams J, Romero R. Epidemiology and causes of preterm birth. Lancet. 2008;371(1):75-84

4. Longo S, Bollani L, Decembrino L, Comite A, Angelini M, Stronati M. Shortterm and long-term sequelae in intrauterine growth retardation (IUGR). J Matern Fetal Neonatal Med. 2012;26(3):222-5.
5. Levine T, Grunau R, McAuliffe F, Pinnamaneni R, Foran A, Alderdice F. Early childhood neurodevelopment after intra-uterine growth restriction: a systematic review. Pediatrics. 2015;135(1):1-18.

6. Lliodromiti S, Mackay D, Smith G, Pell J, Nelson S. Apgar score and the risk of cause-specific infant mortality: a population-based cohort study. Lancet. 2014;384(1):1749-55

7. American Academy of Pediatrics Committee on Fetus and Newborn, and American College of Obstetricians and Gybecologists Committee on Obstetric Practice. The Apgar Score. Pediatrics. 2015;136(4):819-22.

8. Langridge A, Glasson E, Nassar N, Jacoby P, Pennell C, Hagan R, Bourke J, Leonard H, Stanley F. Maternal conditions and perinatal characteristics associated with autism Spectru Dlsorder and intellectual disability. PLoS One. 2013:8(1):1-10.

9. Schieve L, Clayton H, Durkin M, Wingate M, Drews-Botsch C. Comparison of perinatal risk factors associated with autism Spectrum Disorder (ASD), intellectual disability (ID) and co-occuring ASD and ID. J Autism Dev Disord. 2015;45(1):2361-72.

10. Dudova I, Kasparova M, Markova D, Zemankova J, Beranova S, Urbanek T, Hrdlicka M. Screening for autism in preterm children with extremely low and very low birth weight. Neuropsychiatr Dis Treat. 2014;10:277-82.

11. Von Katterfeld B, Li J, McNamara B, aL A. Obstetric profiles of foreign-born women in Western Australia using data linkage, 1986-2006. Aust N Z J Obstet Gynaecol. 2011;51:225-32.

12. Fuster V, Zuluaga P, Colantonio S, Roman-Busto J. Regional differences in low birth weight in Spain; biological, demographic and socioeconomic variables. J Biosoc Sci. 2015;47:90-104.

13. Shah R, Ray J, Taback N, Meffe F, Glazier R. Adverse pregnancy outcomes among foreign-born Canadians. J Obstet Gynaecol Can. 2011;33(3):207-2015.

14. Bakken K, Skjeldal O, Stray-Pedersen B. Immigrant from conflict-zone countries: an observational comparisoon study of obstetric outcomes in a low risk maternity ward in Norway. BMC Pregnancy Childbirth. 2015;15:163-75.

15. Elo I, Vang Z, Culhane J. Variation in birth outcomes by mothers country of birth among non-hispanic black women in the United States. Matern Child Health J. 2014;18:2371-81.

16. Pedersen G, Mortensen L, Gerster M, Rich-Edwards J, Andersen A. Preterm birth and birthweight for gestational age among immigrant women in Denmark 1978-2007: a Nationwide registry study. Paediatr Perinat Epidemiol. 2012;26(1):534-42.

17. Gialloreti L, Benvenuto A, Benassi F, Curatolo P. Are caesarean sections, induced labor and oxytocin regulation linked to autism Spectrum disorders? Med Hypothesis. 2014;82(1):713-8.

18. Von Katterfeld B, McNamara B, aL A. Maternal and neonatal outcomes associated with gestational diabetes in women from culturally and linguistically diverse backgrounds in Western Australia. Diabet Med. 2011;29:372-7.

19. Von Katterfeld B, Li J, McNamara B, aL A. Perinatal complications and cesarean delivery among foreign-born and Australian-born women in Western Australia, 1998-2006. Int J Gynecol Obstet. 2012;116:153-7.

20. Leonard H, Glasson E, Nassar N, Whitehouse A, Bebbington A, Bourke J, Jacoby P, Dixon G, Malacova E, Bower C, et al. Autism and intellectual disability are differentially related to sociodemographic background at birth. PLoS One. 2011;6(3):e17875.

21. Urquia M, Sorbye I, Wanigaratne S. Birth-weight charts and immigrant populations: a critical review. Best Pract Res Clin Obstet Gynaecol. 2016;32 69-76.

22. Gagnon A, Zimbeck M, Zeitlin J, the ROAM Collabortion. Migration to western industrialised countries and perinatal health: a systematic review. Soc Sci Med. 2009;69:934-46.

23. Overseas born Aussies highest in over a century [https://www.abs.gov.au/ ausstats/abs@.nsf/lookup/3412.0Media\%20Release12014-15]. Accessed 10 Mar 2016.

24. Department of Immigration and Border Protection D. Australia's Humanitarian Programme 2014-2015 and Beyond. Canberra: Australian Government; 2014.

25. Department of Immigration and Citizenship D. 2015-16 Migration Programme Report. Programme year to 30 June 2016. Canberra: Australian Government; 2016. p. 1-15.

26. Smits J, Monden C. Twinning across the developing world. PLoS One. 2011; 6(9):225239

27. United Nations Committe for Development Policy, Development Policy and Analysis Division, Department of Economic and Social Affairs. List of Least Developed Countries (as of May 2016). Geneva: United nations; 2016. 
28. United Nations. World economic situation and prospects 2012: Country Classification. Geneva: United Nations; 2012. p. 129-40.

29. Composition of macro geographical (continental) regions, geographical sub-regions, and selected economic and other groupings [https://unstats. un.org/unsd/methodology/m49/accessed07/06/2016]. Accessed 7 June 2016.

30. Fernald L, Kariger P, Engle P, Raikes A. In: Fernald LKP, Engle P, Raikes A, editors. Examining early child development in low- income countries: a toolkit for the assessment of children in the first five years of life. Washington DC: The World Bank; 2009. p. 1-210.

31. Countries and Economies [http://data.worldbank.org/country]. Accessed 8 Feb 2016.

32. World Bank Country and Lending Groups [https://datahelpdesk.worldbank.org/ knowledgebase/articles/906519-world-bank-country-and-lending-groups]. Accessed 8 Feb 2016.

33. Information Paper: An introduction to socio-economic indexes for areas (SEIFA) 2016 [http://www.abs.gov.au/AUSSTATS/abs@.nsf/Lookup/2039. OMain Features42006?opendocument\&tabname $=$ Summary\&prodno $=2039$. 0\&issue $=2006 \&$ num $=\& v i e w=-$ Figure\%202.2\%20IRSAD\%2C\%2 OInterpretation]. Accessed 18 Aug 2015.

34. Milne E, Laurvick C, Blair E, Bower C, de Klerk N. Fetal growth and acute childhood leukemia: looking beyond birth weight. Am J Epidemiol. 2007; 166(1):151-9.

35. Blair E, Liu Y, de Klerk N, Lawrence D. Optimal fetal growth for caucasian singleton and assessment of appropriateness of fetal growth: an analysis of a total population perinatal database. BMC Pediatr. 2005:5(13):1-12.

36. Leonard H, Nassar N, Bourke J, Blair E, Mulroy S, Klerk N, Bower C. Relation between intrauterine growth and subsequent intellectual disability in a tenyear population cohort of children in Western Australia. Am J Epidemiol. 2008;167(1):103-11.

37. Sayers $\mathrm{S}$, Mott $\mathrm{S}$, Singh $\mathrm{G}$. Fetal growth restriction and 18-year growth and nutritional status: aboriginal birth cohort 1987-2007. Am J Hum Biol. 2011; 23(417-419):417.

38. Kandasamy Y, Tanchi P, Edmounds L. Small for gestational age and low birth weight term admissions to a tertiary perinatal Centre in Northern Queensland, Australia. J Immigr Minor Health. 2015;17(1):227-31.

39. Sayers S, Singh G, Mott S, McDonnell J, Hoy W. Relationships between birthweight and biomakers of chronic disease in childhood: aboriginal birth cohort study 1987-2001. Paediatr Perinat Epidemiol. 2009;23(1):548-56.

40. Langridge AT, Li J, Nassar N, Stanley FJ. Community-level socioeconomic inequalities in infants with poor fetal growth in Western Australia, 1984 to 2006. Ann Epidemiol. 2011;21(7):473-80.

41. Holman C, Bass J, Rosman D, Smith M, Semmens J, Glasson E, Brook E, Trutwin B, Rouse I, Watson C, et al. A decade of data linkage in Western Australia: strategic design, applications and benefits of the WA data linkage system. Aust Health Rev. 2008;32(4):766-77.

42. Pereira $G$, Blair $E$, Lawrence D. Validation of a model for optimal birth weight: a prospective study using serial ultrasounds. BMC Pediatr. 2012;12:73.

43. Paxton G, Kay M, Correa-Velez I. Lost and found: improving ascertainment of refugee- background Australians in population datasets. J Med J Aust. 2012;10:552.

44. Liu C, Urquia M, Cnattingius S, Hjern A. Migration and preterm birth in war refugees: a Swedish cohort study. Eur J Epidermiol. 2014;29:141-3.

45. Williams $\mathrm{K}$, Helmer M, Duncan G, Peat J, Mellis C. Perinatal and maternal risk factors for autism spectrum disorders in New South Wales, Australia. Child Care Health Dev. 2008;34(2):249-56.

\section{Publisher's Note}

Springer Nature remains neutral with regard to jurisdictional claims in published maps and institutional affiliations.

Ready to submit your research? Choose BMC and benefit from:

- fast, convenient online submission

- thorough peer review by experienced researchers in your field

- rapid publication on acceptance

- support for research data, including large and complex data types

- gold Open Access which fosters wider collaboration and increased citations

- maximum visibility for your research: over $100 \mathrm{M}$ website views per year

At BMC, research is always in progress.

Learn more biomedcentral.com/submissions 